\title{
Safety and Antioxidant Properties of Five Probiotic Lactobacillus plantarum Strains Isolated from the Digestive Tract of Honey Bees
}

\author{
Chancel Hector Momo Kenfack ${ }^{1}$, François Zambou Ngoufack ${ }^{1, *}$, Pierre Marie Kaktcham¹, \\ Yan Rui Wang', Taicheng Zhü ${ }^{2}$, Li Yin ${ }^{2}$ \\ ${ }^{1}$ Laboratory of Biochemistry, Food Science, and Nutrition (LABPMAN), Department of Biochemistry, Faculty of Science, \\ University of Dschang, P.O. Box: 67 Dschang, Cameroon \\ ${ }^{2}$ China Academy of Science (CAS) Key Laboratory of Microbial, Physiological and Metabolic Engineering, \\ Institute of Microbiology, China \\ *Corresponding author: fzambou@yahoo.fr
}

\begin{abstract}
The objective of this study was the evaluation of safety, adhesion and antioxidant properties of five L. plantarum strains isolated from the digestive tract of honey bees. The set of variables generated from this study was submitted to a normalized Pearson (n) Principal Component Analysis (PCA). The five L. plantarum strains showed no gelatinase activity and were checked to be non-hemolytic. They were susceptible to chloramphenicol, amoxicillin, penicillin $\mathrm{G}$ and tetracycline. The MICs were ranged between 1-4 $\mu \mathrm{g} / \mathrm{ml}$ for erythromycin and resistance was observed among $80 \%$ of strains (L. plantarum H15, H21, H24, and H28). A significantly high percentage of hydrophobicity in n-hexane was observed with $L$. plantarum $\mathrm{H} 47(71.99 \pm 1.39)$ followed by $L$. plantarum H28 (65.68 \pm 1.49 ) while the highest value in the presence of chloroform, belonging L. plantarum $\mathrm{H} 24$ and L. plantarum H28 (28.39 \pm 0.88 and $23.58 \pm 0.68$ respectively). Both the Intact Cells (ICs) and Cell-Free Supernatants (CFSs) of $L$. plantarum H24 strain displayed the higher percentage (p 0.05) of DPPH radical scavenging activity $(76.58 \pm 0.55 \%$ and $59.13 \pm 4.01 \%$ respectively). With the HRS activity, ICs of L. plantarum H24 strain exhibited the highest (p > $0.05)$ activity $(73.37 \pm 0.62 \%)$ whereas, the CFS of $L$. plantarum $\mathrm{H} 47$ was the best $(29.49 \pm 1.28 \%, \mathrm{p}>0.05)$. In allpurpose, based on PCA, L. plantarum H28, and $L$. plantarum $\mathrm{H} 24$ seem to be quite promising as they possessed the best properties tested. Accordingly, they can be chosen as representative of the potential probiotic strains.
\end{abstract}

Keywords: honeybee, lactic acid bacteria, safety, hydrophobicity, antioxidant

Cite This Article: Chancel Hector Momo Kenfack, François Zambou Ngoufack, Pierre Marie Kaktcham, Yan Rui Wang, Taicheng Zhu, and, Li Yin, "Safety and Antioxidant Properties of Five Probiotic Lactobacillus plantarum Strains Isolated from the Digestive Tract of Honey Bees.” Journal Name, vol. 6, no. 1 (2018): 1-8. doi: 10.12691/ajmr-6-1-1.

\section{Introduction}

Lately, the use of probiotics has become gradually popular. Lactic acid bacteria (LAB) are known as microorganisms that have probiotic attributes and have been classified as GRAS (generally recognized as safe). New strains of probiotics LAB with novel functional properties are of interest. The documented potential benefits comprised prevention of intestinal disorders, modulation of the immune system, increase resistance to infection, promotion of good digestion, inhibit the growth of harmful and pathogen bacteria, lowering of serum cholesterol level $[1,2,3]$. LABs, especially lactobacilli, are the genus commonly used as probiotics, of their harmless character and their frequent use in food production [4].

It has been recognized that high concentration of cholesterol in the blood of humans constitute a risk factor in cardiovascular diseases (CVDs), a major cause of death in many countries $[5,6]$. The prevalence of CVD in developed and developing countries remains high and is increasing [7]. According to WHO, in 2020, over $40 \%$ deaths should be attributed to cardiovascular disease [8]. Long-standing high levels of blood cholesterol could lead to atherosclerosis and may consequently cause a major threat to the establishment of CVDs. As reported by WHO, $10 \%$ diminution in serum cholesterol in men aged 40 , could within 5 years, reduce the prevalence of heart disease by $50 \%$ [9]. Right now, there is a growing awareness of the use of bile salt hydrolase activity of lactobacilli since they might potentially perform the reduction of serum cholesterol level in humans [10].

The oxidation and oxidative processes of low-density lipoproteins (LDL) are assumed to be a significant factor in atherosclerosis genesis [11]. The high rate of this oxidation may be due to the dissimilarity between elimination and production of free radicals reactive and oxygen species (ROS); which are above all removed by the endogenous antioxidant protection system, resulting to oxidative stress [12]. To date, assessment and selection of natural molecules or substances that have or contain 
antioxidant power is the novel research tendency of medicine, biology and also in food science. Lately, some studies described the performance of selected probiotic strains of their antioxidant capacity $[13,14]$.

Bile salt hydrolytic activity is well recognized as the contributing factor that may permit resistance of the LABs and to the toxicity of conjugated salts in the duodenum, and consequently, is an essential colonization factor [15]. Adhesion to intestinal mucus is a wanted attribute for probiotic bacteria, as it increases persistence in the GIT (Gastrointestinal Tract) and the aptitude to colonize intestine efficiently [16,17]. In vitro assay facilitates a preliminary selection of strains with probiotic potential, focusing on significant features as adhesion and safety properties, antibiotics susceptibility.

The promising probiotic properties of $L$. plantarum strains isolated from honeybee tract in Menoua division (Cameroon) have been done in our previous study. They exhibited high resistance to low $\mathrm{pH}$, resist to bile salt and have the good hydrolytic activities on the oxgall bile salts. The present study was aimed to evaluate safety properties, antibiotics susceptibility, and adhesion property by determination of their cell surface characteristics, of the 5 L. plantarum strains isolated from honeybee's tracts. Also, determine their antioxidant activity using DPPH free radical and Hydroxyl radicals scavenging assays.

\section{Materials and Methods}

\subsection{Bacterial Strains and Growth Conditions}

This study was performed using five (5) LAB strains isolated from honeybee tract (Table 1). They can survive to low $\mathrm{pH}$ and are resistant to $0.3 \%$ bile salts. Their BSH activity may contribute to lower the cholesterol levels. The strains were earlier identified by $16 \mathrm{~S}$ rRNA gene sequencing and were deposited in the NCBI GenBank (http://blast.ncbi.nlm.nih.gov/Blast.cgi) to acquire their nucleotide sequences accession numbers. L. plantarum strains were grown in MRS broth (Difco) [18] at $37^{\circ} \mathrm{C}$ for 18-24h. Staphylococcus aureus ATCC 25923 and Streptococcus mutans DSM 20523 were cultivated in Muller Hinton (Tulip Diagnostics, India) broth at $37^{\circ} \mathrm{C}$ for $18 \mathrm{~h}$. All these strains were maintained at $-80{ }^{\circ} \mathrm{C}$ in the suitable cultivation broth (MRS or Muller Hinton) containing 20\% (v/v) glycerol.

Table 1. Lactic Acid Bacteria Strains Used in this Study

\begin{tabular}{|c|c|c|}
\hline Strains & Origin & $\begin{array}{c}\text { Accession } \\
\text { Number }\end{array}$ \\
\hline Lactobacillus plantarum H15 & Penka-Michel centre & KU886171 \\
\hline Lactobacillus plantarum H21 & Penka-Michel centre & KU886168 \\
\hline Lactobacillus plantarum H24 & Penka-Michel centre & KU886174 \\
\hline Lactobacillus plantarum H28 & Penka-Michel centre & KU886169 \\
\hline Lactobacillus plantarum H47 & Bamendou, QtNguim & KU886166 \\
\hline
\end{tabular}

\subsection{Safety Assessment of the Strains}

\subsubsection{Production of Gelatinase}

The assessment of gelatinase activity of the strains was carried out as described by Harrigan and McCance [19]. Two microliters of a $6 \mathrm{~h}$ old culture of the strain was spotted onto the surface of nutrient agar containing 7\% (w/v) gelatin (Oxoïd). The plates were incubated in anaerobic conditions at $37^{\circ} \mathrm{C}$ (Incubator, Techmel TT9052, USA) for $48 \mathrm{~h}$ after which they were swamped with saturated ammonium sulfate solution and observed for clear zones surrounding colonies. Staphylococcus aureus ATCC 25923 was used as positive control. The assay was performed in triplicate

\subsubsection{Hemolytic Activity}

The hemolytic character of each strain was investigated using the method described by Gerhardt et al. [20] with slight modifications. Two $\mu \mathrm{l}$ of a $6 \mathrm{~h}$ old culture was spotted into sterile blood agar which was prepared by adding 7\% sheep-blood (freshly collected in a sterilized EDTA-containing tube) sheep blood agar base (Oxoïd) at $25^{\circ} \mathrm{C}$. Plates were anaerobically incubated for $48 \mathrm{~h}$ at $37^{\circ} \mathrm{C}$ after which they were observed for the recording characteristics as follow: $\alpha$-hemolysis (a green zone around colonies), $\beta$-hemolysis (clear zones around colonies) and $\gamma$-hemolysis (no halo around colonies). A strain of Streptococcus mutans DSM 20523 was used as positive control. The assay was carried out in triplicate

\subsubsection{Antibiotic Susceptibility Assay}

Minimal inhibitory concentration (MIC) was assessed using microdilution method according to the national committee for clinical laboratory standards (NCCLS) guidelines. The antibiotics used were streptomycin, tetracycline, erythromycin, chloramphenicol, penicillin G, and amoxicillin. The range of concentrations for each tested antibiotic varied according to the breakpoints defined for Lactobacillus by EFSA [21]. Overnight-cultured colonies of each strain were suspended into MRS broth to approximately 0.5 Mc Farland standards. A volume of 100 $\mu \mathrm{l}$ of the obtained suspension was inoculated into each MRS broth containing each antibiotic. The microplates containing the mixture were incubated at $37^{\circ} \mathrm{C}$ for $24 \mathrm{~h}$. The tests were conducted in triplicate for each strain.

\subsection{Determination of Cell Surface Characteristics}

\subsubsection{Cell Surface Hydrophobicity}

The cell surface hydrophobicity of the LAB was assessed by measuring adhesion to hydrocarbons (MATH) as described by Ji et al. [22]. Bacteria strains cultured at $30^{\circ} \mathrm{C}$ for $18 \mathrm{~h}$ in MRS broth were collected by centrifugation $\left(5000 \mathrm{~g} / 10 \mathrm{~min} / 4^{\circ} \mathrm{C}\right)$ was washed twice with physiological solution and resuspended in the same preparation. The optical density of the suspension was measured at $580 \mathrm{~nm}$ (reading 1) (UV/VIS spectrophotometer, Perkin Elmer Instruments). Then, this bacterial suspension was added to either n-hexane or chloroform at a ratio 1:1 correspondingly. That mixture was mixed by vortexing for $2 \mathrm{~min}$ and left at room temperature for $30 \mathrm{~min}$ to split the layer. After this period, the water-soluble layer was also measured at the same wave length as the bacterial suspension (reading 2). This assay was performed in three replicates. Hydrophobicity (H) was calculated using equation (1). 


$$
H(\%)=\left[\frac{(\text { OD reading1 }- \text { OD reading2) }}{\text { OD reading1 }}\right] \times 100 .
$$

\subsubsection{Auto-Aggregation}

The auto-aggregation test was done according Solieri et al. [23].One $\mathrm{ml}$ of $4 \mathrm{Mc}$ Farland cell suspensions in PBS buffer ( $\mathrm{pH} 7.4 ; 0.02 \mathrm{mM}$ ) was well mixed by vortexing for $10 \mathrm{~s}$ and incubated at room temperature for $5 \mathrm{~h}$. Then, $0.1 \mathrm{ml}$ aliquot of this suspension was taken and mixed with $500 \mu$ lof PBS buffer and the absorbance at $600 \mathrm{~nm}$ was measured. Auto-aggregation (Auto-A\%) was done as percent decrease in the absorbance after $5 \mathrm{~h}(\Delta \mathrm{Abs} \times 100)$ relative to that of original suspension $\left(\mathrm{Abs}_{\mathrm{t} 0}\right)$ as shown by equation (2)

$$
\text { Auto }-\mathrm{A}(\%)=\frac{\Delta \mathrm{Abs}}{\mathrm{Abs}_{\mathrm{t} 0}} \mathrm{x} 100 .
$$

\subsection{Determination of LAB Strains Antioxidant Activity}

\subsubsection{Preparation of Intact Cells (ICs) and Cell-Free Supernatants (CFSs)}

An overnight grown culture $\left(37^{\circ} \mathrm{C}\right.$ for $\left.18 \mathrm{~h}\right)$ of the $\mathrm{LAB}$ strains was centrifugated $\left(5000 \mathrm{~g} / 10 \mathrm{~min}\right.$ at $\left.4^{\circ} \mathrm{C}\right)$ to obtain CFSs. Then, the resulting pellet of each strain was adjusted to approximately $10^{9} \mathrm{CFU} / \mathrm{ml}$ in PBS (pH7.4, $0.02 \mathrm{mM}$ ) before used as ICs. Both ICs and CFSs of the strains were submitted to different antioxidant assays, specifically DPPH free radical scavenging and hydroxyl radical scavenging ability assays.

\subsubsection{Determination of 2,2-Diphenyl-1-Picryl-Hydrazyl (DPPH) Free Radical Scavenging Activity}

The DPPH free radical scavenging activity was evaluated as described by Zhang et al. [24] with slight modification. Briefly, ICs or CFSs $(0.8 \mathrm{ml})$ was mixed with $1 \mathrm{ml}$ of freshly prepared DPPH solution $(0.2 \mathrm{mM}$ in ethanol) and allowed to react for $30 \mathrm{~min}$. Either deionized water or PBS constitutes blank samples. The scavenged DPPH activity was at that moment monitored, by measuring the decrease in absorbance at $517 \mathrm{~nm}$. This activity was calculated by equation (3).

$$
\text { Scavenging effect }(\%)=\frac{A_{517 n m(\text { sample) }}}{A_{517 n m(b l a n k)}} \times 100 \text {. }
$$

\subsubsection{Hydroxyl Radical Scavenging Ability (HRS)}

The HRS activity of ICs and CFSs was analyzed as described by Xing et al. [25]. A sample (ICs or CFSs, MRS broth, $1 \mathrm{ml}), 1,10$-phenanthroline $(2.5 \mathrm{mM}, 1 \mathrm{ml}$; Sigma), $\mathrm{FeSO}_{4}(2.5 \mathrm{mM}, 1 \mathrm{ml})$, and $\mathrm{PBS}$ (pH 7.4, 0.02 $\mathrm{mM}, 1 \mathrm{ml}$ ) was mixed. The reaction was started by adding $\mathrm{H}_{2} \mathrm{O}_{2}(20 \mathrm{mM}, 1 \mathrm{ml})$. This mixture was incubated at $37^{\circ} \mathrm{C}$ for 90 min. HRS activity was monitoring by identifying the increase in absorbance at $536 \mathrm{~nm}$ by using a Spectrophotometer. The percentage of resistance to hydroxyl radicals was calculated using the following equation (4).

$$
\text { HRS activity }(\%)=\frac{A_{S}-A_{c}}{A_{b}-A_{c}} \times 100
$$

Where, AS and AC represent the absorbance of the sample and the control solution (deionized water was used at the same amount in place of the sample) respectively, and $\mathrm{Ab}$ is the absorbance of the solution with no samples and $\mathrm{H}_{2} \mathrm{O}_{2}$.

\subsection{Data Processing and Statistical Analysis}

The assays were repeated on three independent times. The mean values, as well as standard deviation were calculated from the obtained data. All these data were compared by Duncan's multiple range method at the significance level of $\mathrm{p}<0.05$. Statistical analysis was done using the software GraphPad Instat (GraphPad Software Inc, V3). The set of variables was reduced by a factor extraction method using principal component analysis (PCA). The Kaiser's rule was applied to the selection of the number of principal components. The cases introduced in the analysis were the $5 \mathrm{LAB}$ strains whereas the discriminating variables were the cell surface characteristic (auto-aggregation, hydrophobicity) and antioxidative ability (DPPH, HRS). The XLSTAT2007.8.04 software (Addinsoft, Paris, France, http://www.slstat.com) was used, and a normalized Pearson (n) PCA applied.

\section{Results}

\subsection{Safety Properties of the Strains}

LAB strains have been assessed for their gelatinase and hemolytic activities. The results reveal that all the five strains showed no gelatinase activity, and were checked to be non-hemolytic as pathogenicity factors.

The MICs of the antibiotics are available in Table 2. This table shows the MICs values of the 5 LAB strains to cell wall inhibitors (amoxicillin and penicillin G) and protein synthesis inhibitors (erythromycin, tetracycline, streptomycin, and chloramphenicol). All the LAB strains assayed $(100 \%)$ were susceptible to chloramphenicol (MICs $<8 \mu \mathrm{g} / \mathrm{ml}$ ) and tetracycline (MICs $\leq 32 \mu \mathrm{g} / \mathrm{ml}$ ). For erythromycin, the MICs of our strains were ranged between $1-4 \mu \mathrm{g} / \mathrm{ml}$. In the case of this antimicrobial substance tested, resistance was observed among 4 of our strains (80\%); i.e., L. plantarum H15, H21, H24 and H28 when comparing their MICs with the cut-off value of EFSA. Since the cut-off values of some antibiotics (penicillin G, amoxicillin) are not accounted in the European Food Safety Authority (EFSA) guidelines for testing lactobacilli, the breakpoint values suggested by authors took into account. For these antibiotics, results were appreciated according to the cut-off values indicated by Charteris et al. [26]. Thus, the breakpoint of penicillin was chosen as16 $\mu \mathrm{g} / \mathrm{ml}$ and that of amoxicillin as 32 $\mu \mathrm{g} / \mathrm{ml}$. Our results showed that all the five L. plantarum strains tested $(100 \%)$ were susceptible to amoxicillin and penicillin. For aminoglycoside streptomycin, the strains showed MICs distribution between $<0.5$ and $4 \mu \mathrm{g} / \mathrm{ml}$. 
Table 2. Minimal Inhibitory Concentration (MIC) Against the LAB Strains

\begin{tabular}{ccccccc}
\hline \multirow{2}{*}{ Strains } & \multicolumn{7}{c}{ MICs $(\boldsymbol{\mu g} / \mathbf{m l})$} \\
\cline { 2 - 7 } & $\mathrm{S}$ & $\mathrm{E}$ & $\mathrm{T}$ & $\mathrm{C}$ & $\mathrm{P}$ & $\mathrm{A}$ \\
\hline L. plantarum H15 & $<0.5$ & 4 & 8 & 8 & 4 & 16 \\
\hline L. plantarum H21 & 2 & 4 & 8 & 8 & 2 & 16 \\
\hline L. plantarum H24 & $<0.5$ & 2 & 4 & 4 & 2 & 16 \\
\hline L. plantarum H28 & $<0.5$ & 4 & 8 & 8 & 2 & 16 \\
\hline L. plantarum H47 & 4 & 1 & 4 & 4 & 1 & 16 \\
\hline MIC C-O* & n.r & 1 & 32 & 8 & ND & ND \\
\hline
\end{tabular}

S: streptomycin, E: erythromycin, T: tetracycline, C; chloramphenicol, P: penicillin G, A: amoxicillin. *MIC C-O: Minimal inhibitory concentration Cut-Off values by EFSA [21] $(\mu \mathrm{g} / \mathrm{ml})$ for L . plantarum strain. ND: not defined. n.r : not required

Table 3. Cell Surface Properties of the Five Tested LAB Strains

\begin{tabular}{cccc}
\hline \multirow{2}{*}{ Strains } & \multirow{2}{*}{ Auto-A (\%) } & \multicolumn{2}{c}{ H (\%) } \\
\cline { 3 - 4 } & & $\mathrm{n}-H e x a n e$ & Chloroform \\
\hline L. plantarum H15 & $43.66 \pm 0.45^{\mathrm{a}}$ & $45.18 \pm 1.39^{\mathrm{a}}$ & $20.02 \pm 0.72^{\mathrm{a}}$ \\
\hline L. plantarum H21 & $38.57 \pm 3.07^{\mathrm{a}}$ & $31.66 \pm 0.69^{\mathrm{b}}$ & $14.94 \pm 0.86^{\mathrm{b}}$ \\
\hline L. plantarum H24 & $62.66 \pm 3.31^{\mathrm{bc}}$ & $60.86 \pm 1.43^{\mathrm{c}}$ & $28.39 \pm 0.88^{\mathrm{c}}$ \\
\hline L. plantarum H28 & $63.29 \pm 0.22^{\mathrm{b}}$ & $65.68 \pm 1.49^{\mathrm{d}}$ & $23.58 \pm 0.68^{\mathrm{d}}$ \\
\hline L. plantarum H47 & $50.67 \pm 1.20^{\mathrm{c}}$ & $71.99 \pm 1.39^{\mathrm{e}}$ & $20.72 \pm 0.64^{\mathrm{a}}$ \\
\hline
\end{tabular}

In the same column, the value presenting the different letters differ significantly $(p<0.05)$. Auto-A: auto-aggregation, H: hydrophobicity.

\subsection{Cell Surface Characteristics}

In the aim to in vitro evaluate the cell adherence capacity; strains were checked for their cell surface properties (Table 3). The results obtained from the experiments show that L. plantarum $\mathrm{H} 24$ and L. plantarum $\mathrm{H} 28$ displayed upmost auto-aggregation percentage after $5 \mathrm{~h}$ of incubation time (62.66 \pm 3.31 and $63.29 \pm 0.22$ respectively), whereas L. plantarum H21 showed the lower value (38.57 \pm 3.07). The result also reveals that all the strains displayed more cell hydrophobicity in n-hexane than chloroform. The significantly highest percentage of hydrophobicity in n-hexane was exhibited by L. plantarum H47 (71.99 \pm 1.39), followed by
L. plantarum H28 (65.68 \pm 1.49). It results from the hydrophobicity test in the presence of chloroform that all the strains showed percentage between $14 \%$ and $28 \%$. The highest value was belonging to $L$. plantarum $\mathrm{H} 24$ and L. plantarum H28 (28.39 \pm 0.88 and $23.58 \pm 0.68$ respectively) while the percentage belongs to the strain L. plantarum H21 (14.94 \pm 0.86$)$.

\subsection{Antioxidant Activity of the Strains}

\subsubsection{DPPH Free Radical Scavenging Activity}

DPPH is a relatively stable organic radical; it has been broadly used to evaluate antioxidant activities. The results showed that ICs exhibited the highest DPPH radical scavenging rate than that of CFSs (Figure 1). The DPPH radical scavenging activity was comprised between 65\% (L. plantarum $\mathrm{H} 47$ ) and $76 \%$ (L. plantarum $\mathrm{H} 15$, L. plantarum H24, L. plantarum H28). Whereas, with CFSs, the lower value was observed with $L$. plantarum H28 (20.16 $\pm 0.36 \%)$ and the maximum with L. plantarum H24 (59.13 $\pm 4.01 \%)(p>0.05)$. Both the ICs and CFSs of L. plantarum $\mathrm{H} 24$ strain indicated the higher percentage ( $\mathrm{p}>0.05$ ) of DPPH radical scavenging activity (76.58 \pm $0.55 \%$ and $59.13 \pm 4.01 \%$ respectively).

\subsubsection{HRS Activity}

Hydroxyl radicals are estimated to be the mainly reactive oxygen radicals. They can bring on harsh damage in the living cell when reacting with every one biomacromolecule. Consequently, scavenging of hydroxyl radical plays a unique function in dropping oxidative injury. Fenton reaction was used in this work, to evaluate the hydroxyl radicals scavenging activity of the ICs and CFSs of the strains.

As shown in Figure 1 above, among the five strains, tested, the ICs of L. plantarum H24 strain displays the highest $(\mathrm{p}>0.05$ ) hydroxyl radicals scavenging activity (73.37 $\pm 0.62 \%)$ while the lower was $49.04 \pm 2.15 \%$ with L. plantarum H47. However, the CFS of L. plantarum H47 was the best to display the higher hydroxyl radicals scavenging activity than other strains (29.49 $\pm 1.28 \%$, $\mathrm{p}>0.05)$. L. plantarum $\mathrm{H} 15$ showed the lower value with CFS $(8.31 \pm 1.51 \%)(\mathrm{p}<0.05)$.

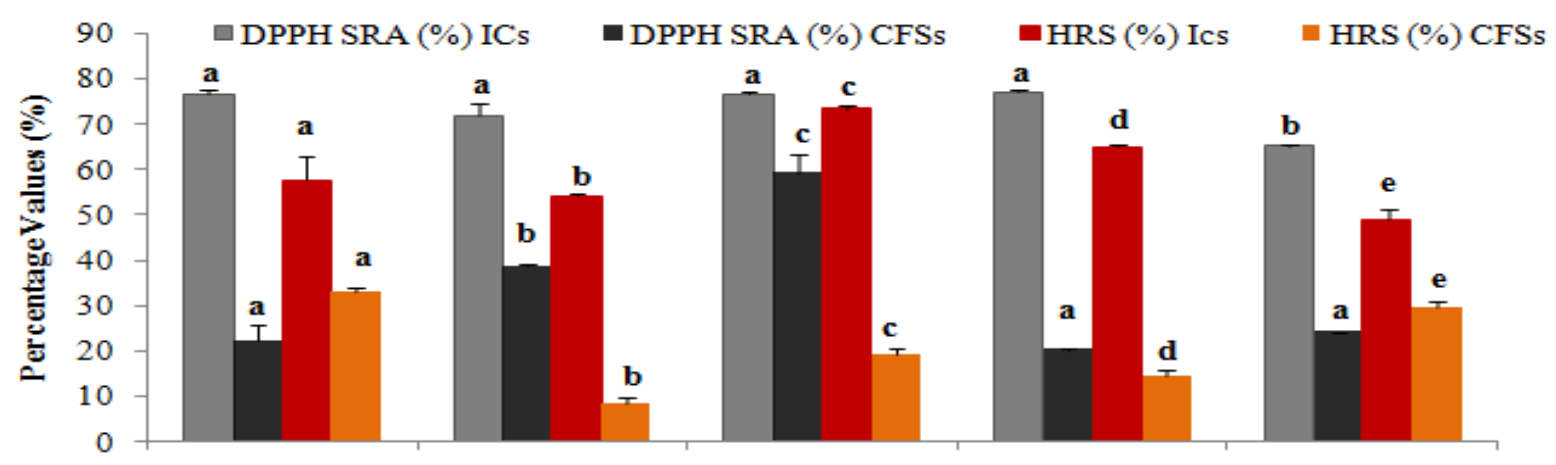

L. plantarum H1 5 L. plantarum H21 L. plantarum H24 L. plantarum H28 L. plantarum H47

\section{Strains}

Figure 1. Scavenging activity of the strain against DPPH free radical and Hydroxyl radicals both with their ICs and CFSs. HRS ICs (\%) :Hydroxyl radical scavenging ability of the intact cells; $\mathrm{HRS}_{\mathrm{CFS}}$ (\%): Hydroxyl radical scavenging ability of the Cell-Free Supernatants; DPPH RSA Picryl-Hydrazyl radical scavenging activity of the intact cells; DPPH RSA CFss $_{2}(\%)$ : 2,2-Diphenyl-1-Picryl-Hydrazyl radical scavenging activity of the Cell-Free Supernatants. ${ }^{\text {a,b,c,de }}$ In the same cross hatch /color, the values presenting the different letters differs significantly ( $p<0.05$ ). Error bars represent the standard deviation 
Table 4. Correlation Matrix between Variables (Pearson (n))

\begin{tabular}{|c|c|c|c|c|c|c|c|}
\hline Variables & Auto-A (\%) & $\mathbf{H}_{\text {chloroform }}(\%)$ & $\mathbf{H}_{\text {n-hexane }}(\%)$ & DPPH RSA $_{\text {Ics }}(\%)$ & DPPH RSA CFSs $(\%)$ & HRS $_{\text {Ics }}(\%)$ & HRS $_{\text {CFSs }}(\%)$ \\
\hline Auto-A (\%) & 1 & & & & & & \\
\hline $\mathbf{H}_{\text {chloroform }}(\%)$ & 0.763 & 1 & & & & & \\
\hline $\mathrm{H}_{\text {n-hexane }}(\%)$ & $0.905^{*}$ & 0.669 & 1 & & & & \\
\hline DPPH SRA ICs (\%) & 0.356 & -0.234 & 0.412 & 1 & & & \\
\hline DPPH SRA CFSs (\%) & 0.211 & -0.276 & 0.409 & 0.411 & 1 & & \\
\hline HRS $_{\text {ICs }}(\%)$ & 0.735 & 0.168 & $0.813^{*}$ & $0.788^{*}$ & 0.698 & 1 & \\
\hline HRS $_{\text {CFSs }}(\%)$ & -0.083 & 0.351 & 0.155 & -0.208 & -0.432 & -0.266 & 1 \\
\hline
\end{tabular}

$\mathrm{H}$ chloroform (\%) : Hydrophobicity on chloroform; $\mathrm{H}_{\text {n-hexane }}(\%)$ : Hydrophobicity on hexane; Auto-A (\%) : Auto-aggregation; HRS ICs $(\%)$ : Hydroxyl radical scavenging ability of the intact cells; HRS CFss (\%) : Hydroxyl radical scavenging ability of the Cell-Free Supernatants; DPPH RSA ICs: 2,2Diphenyl-1-Picryl-Hydrazyl radical scavenging activity of the intact cells; DPPH RSA CFss (\%) :2,2-Diphenyl-1-Picryl-Hydrazyl radical scavenging activity of the Cell-Free Supernatants. *Correlation is significant at the 0.05 level.

\subsection{Principal Component Analysis (PCA)}

PCA was achieved at the final step to investigate the correlation amongst the probiotic properties of the LAB strains (cell surface characteristic and antioxidative ability), and select the promising probiotic. Table 4 presented the Pearson's r coefficient or correlation matrix of variables that were studied. Auto-aggregation was significantly and positively correlated to hydrophobicity on n-hexane (0.905). The other important positively correlations were $\mathrm{H}_{\text {n-hexane }}-\mathrm{HRS}_{\text {ICS }}$ (0.813); DPPH RSA $\mathrm{CFSs}_{\mathrm{s}}-\mathrm{HRS}_{\text {ICS }}$ (0.788). The HRS CFSs $_{\text {was negatively correlated to DPPH RSA }}$ (-0.208), DPPH RSA $A_{\text {CFSs }}(-0.432)$ and HRS $_{\text {ICs }}(-0.266)$.

Two components can be extracted, which together accounted for $80.75 \%$ of the variability as unveiled by the analysis (Figure 2). The PC1 which took account 50.39\% of the total variance separated the strain with a high antioxidative ability and cell surface characteristic from those with a relative low of these properties. The PC2 that accounted for $30.35 \%$ of the total variance separated between cell surface characteristic and antioxidative ability.

Based on the factorial space of PCA, four major groups could be pointed out. The first group is composed of strains L. plantarum $\mathrm{H} 21$ and L. plantarum H15 (negative side of both F1 and F2), characterized by low attributes for the variables considered in the analysis. The second group consists of L.plantarumH47 which exhibited the high value of its hydroxyl radical scavenging ability of its cell-free supernatants. It falls on the negative side of F1 and the positive side of F2. The third group contains L. plantarum H24 which expressed the high value of antioxidative capacity (DPPH and HRS). The fourth group consists of L. plantarum H28 (positive side of both F1 and F2) combined the highest activities for all the variables, and it seems like the best one for the probiotics traits. In general, L. plantarum $\mathrm{H} 28$ and L. plantarum $\mathrm{H} 24$ were quite promising as they possessed the tested properties at their highest levels. Thus, they can be selected as representative of the promising probiotic strains.

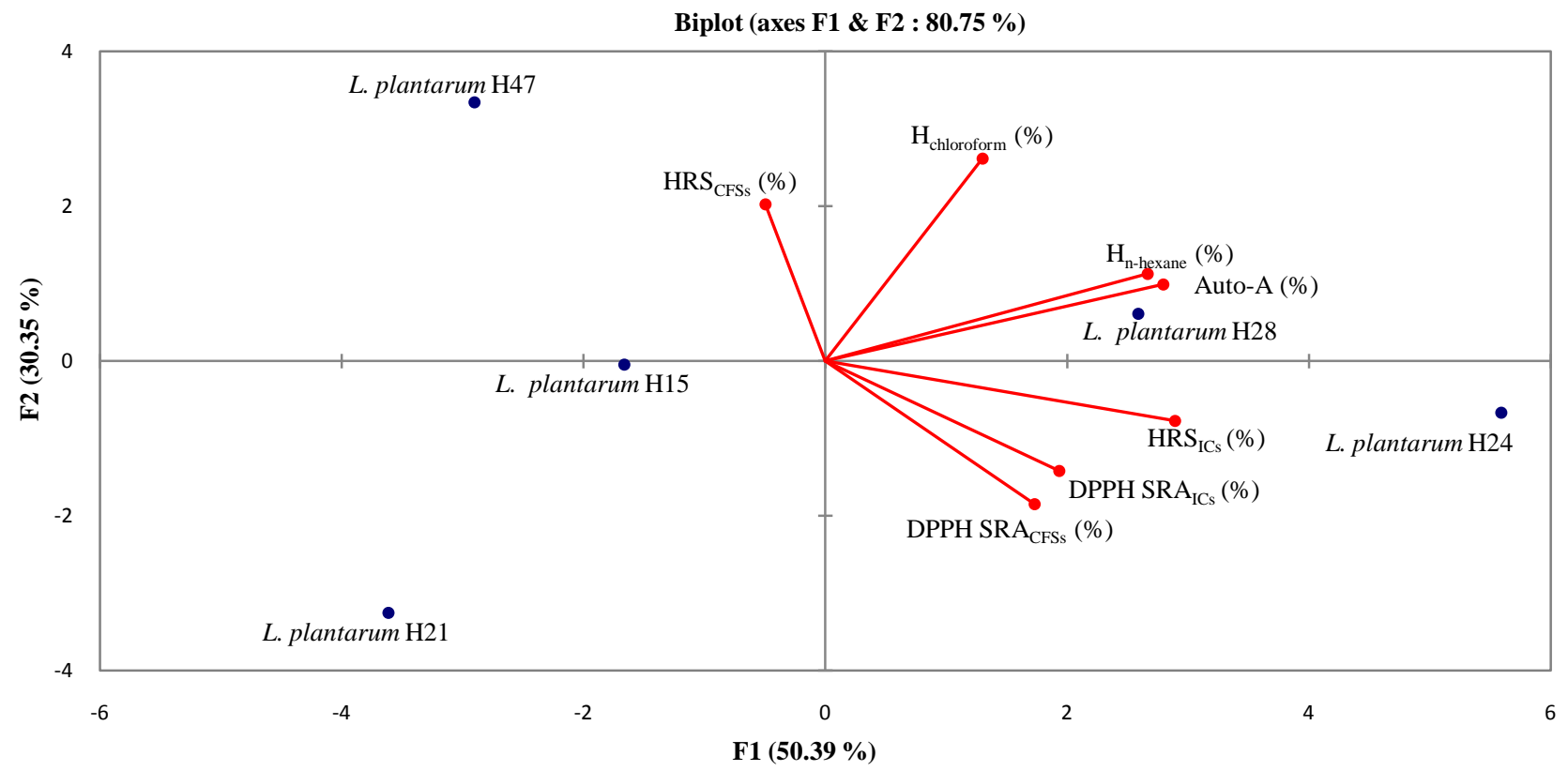

Figure 2. Factorial biplot defined by the principal components 1 and 2 (PC 1: 50.39\%; PC 2: 30.35\%) resulting from the PCA performed on cell surface characteristic and antioxidative ability of the LAB strains. $\mathrm{H}_{\text {chloroform }}(\%)$ : Hydrophobicity on chloroform; $\mathrm{H}_{\mathrm{n} \text {-hexane }}(\%)$ : Hydrophobicity on $\mathrm{n}$-hexane; Auto-A (\%) : Auto-aggregation; HRS $\mathrm{ICs}_{\mathrm{I}}(\%)$ : Hydroxyl radical scavenging ability of the intact cells; HRS $\mathrm{CFSs}_{\mathrm{C}}(\%)$ : Hydroxyl radical scavenging ability of the Cell-Free Supernatants; DPPH RSA ICs $_{\text {: }}$ 2,2-Diphenyl-1-Picryl-Hydrazyl radical scavenging activity of the intact cells; DPPH RSA Diphenyl-1-Picryl-Hydrazyl radical scavenging activity of the Cell-Free Supernatants 


\section{Discussion}

Every strain which would be assumed as a probiotic candidate should be appraised regarding safety aspects. To ensure their safe use in humans the five $L$. plantarum strains were screened for the antibiotic resistance, the hemolytic and the gelatinase activities. Gelatinase activity could disturb the mucoid lining even as hemolysis activity would destroy the epithelial layer [27], and these injuries would be the pathways for infections. In the present study, none of the tested LAB strains presented $\beta$-hemolytic and gelatinase activity. The absence of these activities is a selection criterion for probiotic strains, suggesting that these bacteria are non virulent [28]. Similar results were obtained by Sieladie et al. [3] with L . plantarum strains isolated from raw cow milk in the highlands of Cameroon and by Anas et al. [29], from raw coat's milk in the region of western Algeria.

Probiotic should not carry transferable antibiotic resistance genes. This is one of a key requirement. The resistance to antibiotics varying inside the Lactobacillus genus as an intrinsic or acquisition characteristic, it's a pertinent attribute. A high hazard of horizontal dissemination of resistance genes exist, when the resistance is contracted from an exogenous DNA material [21]. Our result showed that $80 \%$ of the tested strains ( $L$. plantarum $\mathrm{H} 15, \mathrm{H} 21, \mathrm{H} 24$, and $\mathrm{H} 28$ ) were resistant to erythromycin. In the study performed by Cauwerts et al. [30] on the isolated Lactobacillus strains from broiler chickens in Belgian farms, it was reported that $78 \%$ revealed resistance to erythromycin. Chromosomally encoded resistance to this antimicrobial is regular in lactobacillus species [31]. For L. plantarum strains, there are no approved breakpoints with streptomycin. In fact, as commonly known, lactobacilli have a high natural resistance to streptomycin [32]. The resistance to aminoglycosides such as streptomycin is judged to be intrinsic, principally due to the membrane impermeability [33]. All the strains were sensitive to the other remaining antibiotics used. Danielsen and Wind [32] showed that Lactobacillus sp. had been known to be susceptible to several cell wall synthesis inhibitors, such as penicillins. Kaktcham et al. [34] reported that all of the 9 tested $L$. plantarum strains isolated from Cameroonian traditional fermented foods were sensitive to penicillin G, amoxicillin, chloramphenicol, and tetracycline. Through consideration of common concern on the safety of probiotics, i.e., potential transferability of antibiotic-resistance gene, hemolytic and gelatinase activities, L. plantarum strains of this study appear safe for use.

One of the essential criteria for the choice of putative probiotic lactobacillus stains is their adhesion and their ability to colonize the gastrointestinal tract. These requirements may improve their residence time in the intestine and therefore permit to achieve their probiotic effects [35]. Hydrophobicity assessment provides information on the structural properties of the cell surface which is accountable for aggregation and adhesion of the LAB strains [36]. LAB strains with hydrophobicity cell surface and aggregation potential could be more able to adhere to intestinal cells. In this study, hydrophobicity was done by using chloroform as a polar solvent and n-hexane as a non-polar solvent. The results indicated that all the strains had more affinity for n-hexane than chloroform, indicating more hydrophobic cell surface hydrophilic than. Indeed, the presence of hydrophobic components may justify the high affinity to n-hexane. Former studies like those of Zavaglia et al. [37] on the physico-chemistry of microbial have revealed that hydrophilic surfaces are related with the existence of polysaccharides at the cell surface while the occurrence of (glyco-) proteinaceous material results in the higher hydrophobicity. It has been established that bacterial cells with hydrophobicity possess a high affinity for epithelial or mucus adhesion [38]. Base on the studies of Lee and Yii [39], it was acknowledged that bacterial cell is hydrophobic when its adhesion percentage is at least $50 \%$, hydrophile when this percentage is less than $20 \%$ and moderately hydrophobic if the rate is included between these two values. Consequently, we can say that L. plantarum $\mathrm{H} 24$, L. plantarum $\mathrm{H} 28$, and L. plantarum H47 are hydrophobic while $L$. plantarum H15 and L. plantarum H21 hydrophilic.

Auto-aggregation of the same probiotic strains appeared to be essential for their adhesion to intestinal epithelial cells and is correlated with the colonization of gastrointestinal tract via adhesion to this tissue [36,40]. The results of this study have shown that all the strains exhibited variables auto-aggregation percentage varying between $38.57 \%$ and $63.29 \%$ after $5 \mathrm{~h}$. The detected auto-aggregation can be linked to cell surface component. Ramos et al. [41] also analyzed the autoaggregation percentage of $L$. plantarum strains after $5 \mathrm{~h}$, from the Brazilian food products. They reported that these percentages were varied between $27.55 \%$ and $62.92 \%$. Auto-aggregation was significantly and positively correlated to hydrophobicity on n-hexane in our study. Correlation between hydrophobicity and adhesion ability of several lactobacilli was previously indicated in the studies $[42,43]$ Mostly cell surface-associated proteins are involved in aggregation and adhesion even though numerous additional factors existed like polysaccharide, lipoteichoic and teichoic acids [44].

Reactive oxygen species (ROS) are always produced in vivo. When these ROS are generated in excess, or cellular neutralization process is defective, they can cause lipid, protein and nucleic acids injury [13]. Thus, these harmful molecules can lead to cellular oxidative damage, which is related with the biological and pathological process such as carcinogenesis, cirrhosis, inflammation (e.g., arthritis) and atherosclerosis (which can also lead to cardiovascular diseases) [45]. To control reactive radicals, the selection of probiotics and their usage according to their efficiency are essential in the preservation of human health and avoidance of some disease [46,47]. We have attempted with this study to evaluate the antioxidative activity of LAB strains.

The DPPH-RSA assay is commonly used to assess antioxidant activity for the reason of its simplicity, simplicity, sensitivity, rapidity and reproductively compared with other methods [24]. While, hydroxyl radical which is mostly generated from Fenton reaction (through transition metals such as copper $\left(\mathrm{Cu}^{2+}\right)$ and iron $\left.\left(\mathrm{Fe}^{2+}\right)\right)$, has been acknowledged to be the principally dangerous ROS that is accountable for the oxidative damage of biomolecules. Chelating ions may do inhibition of the formation of these compounds by antioxidants [48]. The result of these two 
radical scavenging assays (DPPH and HRS) reveals that all the tested strains presented variable percentage activity and could inhibit the risk of ROS accumulation in vitro. So, some level of inter-specific variation in radical scavenging ability could exist among the five probiotic strains tested. Varying activities in DPPH radical scavenging was also pointed out by Liu and Pan [49] on 12 Lactobacillus strains. Li et al. [50] reported that the $\mathrm{DPPH}$ free radical scavenging rate by the intact cell of the L. plantarum C88 strain was $53.05 \%$ at the dose $10^{10}$ $\mathrm{UFC} / \mathrm{ml}$. In a study analogous to us, Kaur et al. [51] documented about more than $50 \%$ of this scavenging capacity of theYbis, L5 and Yb LAB strain with their ICs. Furthermore, our results showed that ICs exhibited higher DPPH radical scavenging rate than that of CFSs. And the CFSs of our strains also demonstrated comparatively weaker HRS activity than DPPH free radical scavenging activity. This result is consistent with that of Shen et al. [52] and even with the report of Xing et al. [25]. Both the DPPH and HRS methods showed that the ICs of L. plantarum $\mathrm{H} 24$ and L. plantarum H24 displayed high antioxidant activities. Many studies reveal that antioxidant activity of LAB strains might be linked to their production of cell-surface compounds, e.g., lipoteichoic acid from the cell surface of bifidobacteria [53], extracellular polysaccharides by Bifidobacterium animalis RH [54] and Lactococcus lactis subsp . Lactis [55].

\section{Conclusion}

Finally, the five L. plantarum strains isolated from the digestive tract of honey bees present some important probiotics abilities with varying levels. In this study, we attempted to demonstrate that $L$. plantraum strains from the digestive tract of honey bees have antioxidative activity and can be good candidates for epithelial cell adhesion. From the above results and the PCA analysis, we suggested that L. plantarum $\mathrm{H} 24$ and L. plantarum H28 have required in vitro probiotics properties comparable or higher to those that are already known. They are good candidates for complementary analysis with in vivo assays to investigate their possible technological characteristics and their health promotion.

\section{Acknowledgements}

Chinese Academy of Sciences (CAS), Visiting President's International Fellowship Initiative (PIFI) supported this research. Grant N²015VBB051.

\section{Conflict of Interest}

The authors declare no competing interests

\section{References}

[1] Guo, X.H., Kim, J.M., Nam, H.M., Park, S.Y., and Kim, J.M., "Screening lactic acid bacteria from swine origins for multistrain probiotics based on in vitro functional properties", Anaerobe, 16: 321-326, 2010
[2] Dhanasekaran, D., Saha, S., Thajuddin, N., and Panneerselvam, A., "Probiotic effect of Lactobacillus isolates against bacterial pathogens in Claris orientalis", Facta Universitatis Series: Medicine and Biology, 15 (3): 97-102, 2008.

[3] Sieladie, D.V., Zambou, N.F., Kaktcham, P.M., Cresci, A., and Fonteh, F., "Probiotic properties of lactobacilli strains isolated from raw cow milk in the western highlands of Cameroon”, Innov Rom. Food Biotechnol., 9:12-28, 2011.

[4] Whitehead, K., Versalovic, J., Roos, S., and Britton, R.A., "Genomic and Genetic Characterization of the Bile Stress Response of Probiotic Lactobacillus reuteri ATCC 55730”, Appl. Environ. Microbiol., 74 (6): 1812-1819, 2008.

[5] Kuzawa, C.W., and Sweet, E., "Epigenetics and the embodiment of race: developmental origins of US racial disparities in cardiovascular health”, Am. J. Hum. Biol., 21:2-15, 2009.

[6] Ahn, Y.T., Kim, G.B., Lim, K.S., Baek, Y.J., and Kim, H.U., "Deconjugation of bile salts by Lactobacillus acidophilus isolates" Int. Dairy J., 13: 303-311, 2003.

[7] Sudha, M.R., Chauhan, P., Dixit, K., Babu, S., and Jamil, K., "Probiotics as complementary therapy for hypercholesterolemia", Biol. Med., 1 (4):1-13, 2009.

[8] Kumar, R., Grover, S., and Batish, K.V., "Hypocholesterolaemic effect of dietary inclusion of two putative probiotic bile salt hydrolase-producing Lactobacillus plantarum strains in Sprague-Dawley rats”, Br. J. Nutr., 105: 561-573, 2011.

[9] World Health Organization (WHO). Cardiovascular Disease fact sheet: 2013. [online] Available:

http://www.who.int/mediacentre/factsheets/fs317/en/index.html. [Accessed Nov. 19, 2015].

[10] Pereira, D.I., and Gibson, G.R., "Effects of consumption of probiotics and prebiotics on serum lipid levels in humans", Crit. Rev. Biochem. Mol. Biol., 37: 259-281, 2002.

[11] Westhuyzen, J., "The oxidation hypothesis of atherosclerosis: An update”, Ann. Clin. Lab. Sci., 27:1-10, 1997.

[12] Halliwell, B., and Gutteridge, J., "Free radicals in biology and medicine.” Oxford Clarendon Press, 23-30, 1985.

[13] Kullisaar, T., Zilmer, M., Mikelsaar, M., Vihalemm, T., Annuk, H., Kairaneand C., Kilk, A., "Two antioxidative lactobacilli strains as promising probiotics”, Int. Food Microbiol., 72:215-224, 2002.

[14] Annuk, H., Shchepetova, J., Kullisaar, T., Songisepp, E., Zilmer, M., and Mikelsaar, M., "Characterization of intestinal lactobacilli as putative probiotic candidates”, J. Appl. Microbiol., 94: 403-412, 2003.

[15] Shigwedha, N., and Jia, L., "Bifidobacterium in Human GI Tract: Screening. Isolation. Survival and Growth Kinetics in Simulated Gastrointestinal Conditions". In Kongo J. M. (Eds.) Lactic acid bacteria- R \& D for food health and livestock purposes. InTech press. JanezaTrdine 9. 51000 Rijeka. Croatia. 2013, 281-308.

[16] Lavilla-Lerma, L., Pérez-Pulido, R., Martínez-Bueno, M., Maqueda, M., and Valdivia, E., "Characterization of functional, safety and gut survival related characteristics of Lactobacillus strains isolated from farm house goat's milk cheeses”, Int. J. FoodMicrobiol., 163: 136-145, 2013.

[17] Etzold, S., Kober, O.I., MacKenzie, D.A., Tailford, L.E., Gunning, P., Walshaw, J., Hemmings, A.M., and Juge, N., "Structural basis for adaptation of lactobacilli to gastrointestinal mucus”, Environ. Microbiol., 16:888-903, 2014

[18] De Man, J.C., Rogosa, M., and Sharpe, M.E., "A medium for the cultivation of lactobacilli”, J. Appl. Bacteriol., 23: 130-135, 1960

[19] Harrigan, W.F., and McCance, M.E., Laboratory Methods in Food and Dairy Microbiology. Academic Press. London. 1990, $8^{\text {th }}$ edition.

[20] Gerhardt, P., Murray, R.G.E., Costilow, R.N., Nester, E.W., Wood, W.A., Krieg, N.R., and Phillips, G.B., Manual of methods for general bacteriology. American Society for Microbiology. NW Washington, DC 20006, 1981.

[21] European Food Safety Authority (EFSA) Panel on Additives and Products or Substances used in Animal Feed (FEEDAP), Guidance on the assessment of bacterial susceptibility to antimicrobials of human and veterinary importance. EFSA Journal, 2012, 10.

[22] Ji, K., Jang, Y.N., and Kim, T.Y., "Isolation of Lactic Acid Bacteria Showing Antioxidative and Probiotic Activities from Kimchi and Infant Feces”, J. Microbiol. Biotechnol., 25 (9):15681577, 2015

[23] Solieri, L., Bianchi, A., Mottolese, G., Lemmetti, F., and Giudici, P., "Tailoring the probiotic potential of non-starter Lactobacillus 
strains from ripened Parmigiano Reggiano cheese by in vitro screening and principal component analysis”, Food Microbiol., 38:240-249, 2014

[24] Zhang, S., Liu, L., Su, Y., Li, H., Sun, Q., Liang, X., and Lv, J., "Antioxidative activity of lactic acid bacteria in yogurt', Afr. J. Microbiol. Res., 5 (29): 5194-5201. 2011.

[25] Xing, J., Wang, G., Zhang, Q., Liu, X., Gu, Z., Zhang, H., Chen, Y.Q., and Chen, W., "Determining Antioxidant Activities of Lactobacilli Cell-Free Supernatants by Cellular Antioxidant Assay: A Comparison with Traditional Methods", PLoS ONE 10: e0119058, 2015.

[26] Charteris, W.P, Kelly, P.M., Morelli, L., and Collins, J.K, "Antibiotic susceptibility of potentially probiotic Lactobacillus species”, J. Food Prot., 61:1636-1643. 1998

[27] Thakkar, P., Modi, H.A., and Prajapati, J.B. "Isolation, characterization and safety assessment of lactic acid bacterial isolates from fermented food products”, Int. J. Curr. Microbiol. App. Sci., 4 (4): 713-725, 2015.

[28] De Vuyst, L., Foulquie, M.R., and Revets, H., "The role and application of enterococci in food and health", Int. J. Food Microbiol., 84:299-318, 2003.

[29] Anas, M., Ahmed, K., and Mebrouk, K., "Study of the antimicrobial and probiotic effect of Lactobacillus plantarum (P6) isolated from Raw Goat's Milk from the region of Western Algeria”, World Appl. Sci. J., 32 (7): 1304-1310. 2014.

[30] Cauwerts, C.K., Asmans, P.F., Evriese, D.L.A., Aesebrouck, H.F., and. Ecostere, D.A., "Cloacal Lactobacillus isolates from broilers often display resistance toward tetracycline antibiotics”, Microb. Drug Resist., 12:284-288, 2006.

[31] Ashraf, R., and. Shah, N.P., "Antibiotic resistance of probiotic organisms and safety of probiotic dairy products”, Int. Food Res. J., 18 (3):837-853, 2011.

[32] Danielsen, M., and. Wind, A.A., "Susceptibility of Lactobacillus ssp. to antimicrobial agents”, Int. J. Food Microbiol., 82:1-11, 2003.

[33] Charteris, W.P., Kelly, P.M., Morelli, L., and Collins, J.K., "Gradient diffusion antibiotic susceptibility testing of potentially probiotic lactobacilli”, J. Food Prot., 64: 2007-2014, 2001.

[34] Kaktcham, P.M., Zambou, N.F., Tchouanguep, F.M., El-Soda, M., and Choudhary, M.I., "Antimicrobial and Safety Properties of Lactobacilli Isolated from two Cameroonian Traditional Fermented Foods”, Sci. Pharm., 80:189-203, 2012.

[35] Von Ossowski, I., Reunanen, J., Satokari, R., Vesterlund, S., Kankainen, M., Huhtinen, H., Tynkkynen, S., Salminen, S., de Vos, V.M., and Palva, A., "Mucosal adhesion properties of the probiotic Lactobacillus rhamnosus GG SpaCBA and SpaFED pilin subunits”, Appl. Environ. Microbiol., 76:2049-2057, 2010.

[36] Raghavan, K.T., Jacob, A.A., and Chandran, H., "Honey bee Gut flora as a Source of LAB (Lactic Acid Bacteria) with Probiotic Capabilities”, J. Food Technol., 105:126-134, 2013.

[37] Zavaglia, A., Kociubinski, G., Pérez, P., and De Antoni., A.G.G., "Isolation and characterization of Bifidobacterium strains for probiotic formulation”, J. Food Prot., 61:865-873, 1998.

[38] Tuo, Y., Hanli, Y., Ai, L., Wu, Z., Guo, B., and Chen, W.,” Aggregation and adhesion properties of 22 Lactobacillus strains”, J. Dairy. Sci., 96:4252-4257. 2013.

[39] Lee, K.K., and Yii, K.C., "A comparison of three methods for assaying hydrophobicity of pathogenic vibrios”, Lett. Appl. Microbiol., 23: 343-346, 1996.
[40] Kaktcham, P.M., Temgoua, J-B., Zambou, N.F., Diaz-Ruiz, G., Wacher, C., and Pérez-Chabela, M.L., "In Vitro Evaluation of the Probiotic and Safety Properties of Bacteriocinogenic and NonBacteriocinogenic Lactic Acid Bacteria from the Intestines of Nile Tilapia and Common Carp for Their Use as Probiotics in Aquaculture”, Probiotics Antimicro. Prot., 2017.

[41] Ramos, C.L., Thorsen, L., Schwan, R.F., Jespersen, L., "Strainspecific probiotics properties of Lactobacillus fermentum, Lactobacillus plantarum and Lactobacillus brevis isolates from Brazilian food products”, Food Microbiol., 36: 22-29, 2013.

[42] Wadstroum, T., Andersson, K., Sydow, M., Axelsson, L., Lindgren, S., and Gullmar, B., "Surface properties of lactobacilli isolated from the small intestine of pigs", J. Appl. Microbiol., 62: 513-520, 1987

[43] Xu, H., Jeong, H.S., Lee, H.Y, and Ahn, J., “Assessment of cell surface properties and adhesion potential of selected probiotic strains”, Lett. Appl. Microbiol., 49:434-442, 2009.

[44] Goh, Y.J., and Klaenhammer, T.R., "Functional roles of aggregation-promoting-like factor in stress tolerance and adherence of Lactobacillus acidophilus NCFM”. Appl. Environ. Microbiol., 76:5005-5012, 2010.

[45] Lin, M.Y., and Yen, C.L., "Antioxidative ability of lactic acid bacteria”, J. Agric. Food. Chem., 47:1460-1466, 1999.

[46] Songisepp, E., Kals, J., Kullisaar, T., Mändar, R., Hütt, P., Zilmer, M., and Mikelsaar, M., "Evaluation of the functional efficacy of an antioxidative probiotic in healthy volunteers”, Nutr J., 4:22, 2005.

[47] Foligné, B., Dewulf, J., Breton, J., Claisse, O., Lonvaud-Funel, A., and Pot, B., "Probiotic properties of non-conventional lactic acid bacteria: Immunomodulation by Oenococcusoeni”, Int. J. Food Microbiol., 140:136-145, 2010.

[48] Kao, T., and Chen, B., "Functional components in soybean cake and their effects on antioxidant activity”, J. Agricult. Food Chem., 54:7544-7555, 2006.

[49] Liu, C., and Pan, T., "In Vitro Effects of Lactic Acid Bacteria on Cancer Cell Viability and Antioxidant Activity”, J. Food Drug Anal., 18:77- 86, 2010.

[50] Li, S., Zhao, Y., Zhang, L., Zhang, X., Huang, L., Li, D., Niu, C., Yang, Z, and Wang, Q., "Antioxidant activity of Lactobacillus plantarum strains isolated from traditional Chinese fermented foods”, Food Chem., 135:1914-1919, 2012.

[51] Kaur, M., Singh, H., Jangra, M., Kaur, L., Jaswal, P., Dureja, C., Nandanwar, H., Chaudhuri S.R., Raje, M., Mishra, S., and Pinnaka, A.K,. "Lactic acid bacteria isolated from yak milk show probiotic potential”, Appl. Microbiol. Biotechnol., 10:7635-7652, 2017

[52] Shen, Q., Shang, N., and Li, P., "In vitro and in vivo antioxidant activity of Bifidobacterium animalis 01 isolated from centenarians”, Curr. Microbiol., 62: 1097-1103, 2011.

[53] Yi, Z., Fu, Y., Li, M., Gao, K., and Zhang, X., "Effect of LTA isolated from bifidobacteria on D -galactose-induced aging”, Exp. Geron., 44: 760-765. 2009.

[54] Xu, R., Q. Shen, X. Ding, W. Gao, and P. Li., "Chemical characterization and antioxidant activity of an exopolysaccharide fraction isolated from Bifidobacterium animalis RH”, Eur. Food Res. Technol., 232: 231-240, 2011.

[55] Pan, D., and Mei, X., "Antioxidant activity of an exopolysaccharide purified from Lactococcus lactis subsp. Lactis 12”. Carbohydr. Polymers, 80: 908-914, 2010. 